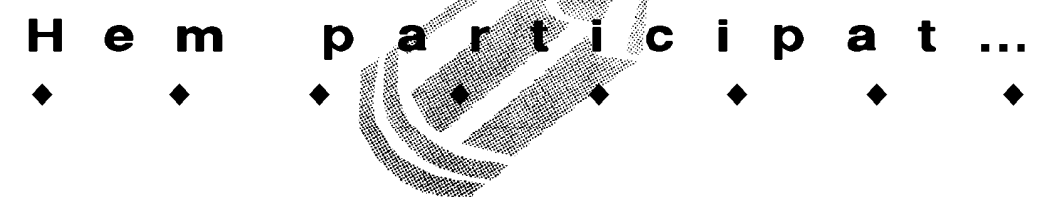

Dinàmica de grups. A càrrec d'Albert Serrat. ICE de la Universitat de Barcelona.

Estratègies per gestionar els conflictes de forma constructiva que ens permetin millorar les relacions dins del grup classe i conèixer les característiques dels alumnes d'un grup classe i com actuar.

Creació d'històries amb eines informàtiques. A càrrec de Josep M. Sero, mestre del CIEP Joc de la Bola de Lleida. Les tecnologies de la informació i la comunicació (TIC) potencien una nova metodologia on els rols del professorat i de l'alumnat han de ser modificats, fent diferents creacions de manera individual $\mathrm{i}$ en treball col.laboratiu.

La didàctica de les llengües estrangeres i les necessitats educatives dels alumnes amb deficiència visual. A càrrec deNeus Salvat, CRE "Joan Amades" (ONCE)

Com treballar amb adults. A càrrec de Tomàs Sentís. Centre municipal de formació d'adults de Tarragona.

Educació i televisió. A càrrec de Txema Campos, professor a l'IES de Vila-seca.

Jacky Verrier, vicedegà de l'Ensenyament de Mestres

\title{
L'ESCOLA CATALANA EN EL CONTEXT DE LA RENOVACIÓ EDUCATIVA ABRIL DE 2002
}

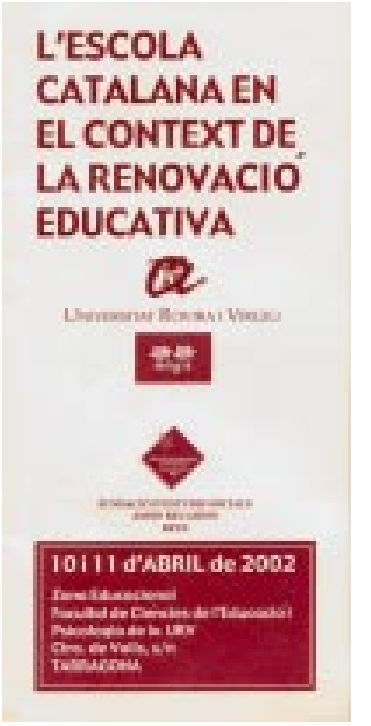

Els ponents van ser diversos, tant des de la vessant de la historiografia com de persones que van viure de primera mà la modernització de l'escola a Catalunya en temps de la República, sense descuidar aquells altres que van ajudar a formar i consolidar el moviment del Col-lectiu d'Escoles per a l'Escola Pública Catalana (CEPEPC) a partir dels anys seixanta. Es comptà amb la presència de persones amb diferents responsabilitats educatives per parlar, en una taula rodona, sobre l'escola del 1975 fins a l'actualitat, i una segona taula rodona, amb representants del collectiu de mestres, pares i alumnes que configuraren l'arrencada de les escoles del CEPEPC a Reus, Valls i Tarragona.

Les jornades van ser d'alt nivell. En una síntesi d'urgència, a l'espera del llibre que recollirà les ponències i les taules rodones, podem avançar els eixos de reflexió dels ponents i de les taules rodones.

- Antoni Gavaldà, professor de Didàctica de les Ciències Socials de la nostra Facultat, parlà de L'escola a la Catalunya del segle XX. Visió històrica i valors que s'han impartit, amb una explicació històrica a partir de les bases que aportà la Institución Libre de Enseñanza, la influència de l'Escola Moderna i els plantejaments de I'Escola Nova. Centrà també l'atenció a diferenciar aquests models d'avançada i apuntà línies de futur.

- Marta Mata, fundadora del moviment de mestres Rosa Sensat, parlà de La preparació dels mestres: Escoles Normals i Professionals, centrant la seva intervenció en dos models de Normals, el que impulsà Joan Bardina a la primera dècada del segle XX i el Pla Professional de la República, pla innovador que quedà estroncat per la guerra.

- Pere Darder exposà el tema La Renovació Pedagògica a Catalunya a partir dels anys seixanta: per quins objectius sorgi, què representà i com es desenvolupà. El seu discurs va ser del tot atractiu, ja que es posà en un període recent, en com es vehiculà la renovació pedagògica a Catalunya a partir de les Escoles d'Estiu i del Moviment de Rosa Sensat, autèntic viver de formació per una escola catalana, lliure i democràtica.

- Josep Roig, Josep Baluja, Joan-Andreu Torres, Rosa Gairal i Àngels Ollé, actuant de moderador Enric Valls, van ser els encarregats de debatre el tema L'escola catalana del 1975 ençà, en l'ajuda a la formació de persones. La particularitat d'aquesta taula rodona va ser que hi havia des de professors d'universitat a mestres d'escola religiosa, mestres d'escola pública, inspector d'ensenyament i components dels Moviments de Renovació Pedagògica; es generà un debat ric d'idees i d'enfocaments per a la formació dels escolars, i sobretot de persones. 


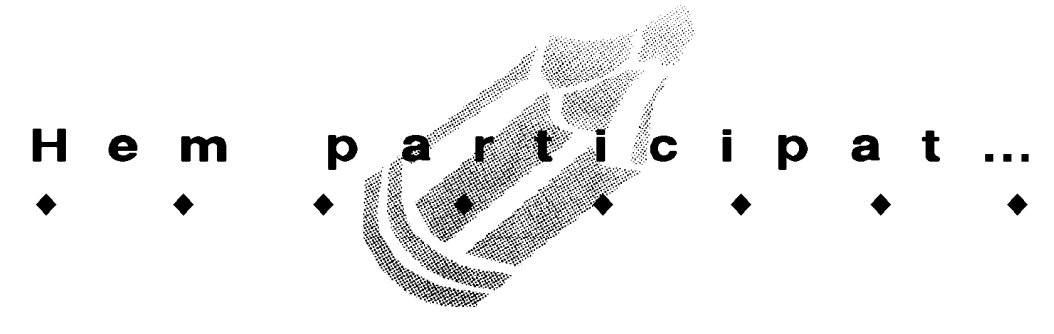

- Pilar Benejam centrà el seu discurs amb la ponència que duia per títol Les aportacions en el camp de la didàctica dels Moviments de Renovació Pedagògica. Parlà des del camp de la didàctica del que representà els MRP, del que aportaren i de la il.lusió que generà el moviment per aprendre a aprendre, demanant que aquesta il-lusió i esperit sigui l'eina de xoc de tot mestre i professor en el present i en el futur.

- Carles Martínez va presentar la ponència El colllectiu d'Escoles per a la Escola Pública Catalana: què representaven iquins objectius tenien?'enfocament del discurs anà dirigit a fer entendre com es vertebrà el moviment, la filosofia que impregnava les escoles i la voluntat de canvi que representaren respecte de l'escola oficial i l'escola confessional, en una perspectiva política que no ajudava gens als canvis. Ressaltà l'apropament a la realitat que es volgué trasmetre en una línia de treball actiu.

- Anna Piguillem parlà de Llums i ombres de la integració a la xarxa de la Generalitat de les escoles del CEPEPC. La seva intervenció, acompanyada de dues mestres del col-lectiu, va situar de forma clara els diversos esperits que conformaven les referides escoles, clarament demostrats quan s'optà per la integració a la xarxa pública de la Generalitat o quan s'optà per continuar com a privades, normalment en format de cooperativa. La idea que transmeteren era que aquestes escoles, en el fons, són les que apostaren per la reforma que ara s'està implantant.

- La darrera sessió va ser una taula rodona en què participaren mestres, pares i alumnes de les escoles del CEPEPC al Camp de Tarragona que s'integraren a la xarxa pública, de les escoles Mowgli i Montsant de Reus, Enxaneta de Valls i Pax de Tarragona. A l'entorn del títol Les antigues escoles del CEPEPC: vint anys a la xarxa pública i amb la coordinació del moderador, Jordi Vallès, hi participaren Montserrat Riera, Joan Roig, Jaume Fernández i Santi Suárez-Baldrís. Les diferents visions aportaren un to amè i entenedor del que volien aquelles escoles, del paper determinant dels pares i de com es veu el seu pas per aquestes escoles, des de la perspectiva d'avui, per part dels alumnes que hi assistiren.

Les Jornades van ser molt ben acollides, el nombre d'estudiants va superar la previsió dels organitzadors, però no va ser pas aquest el fet més remarcable, sinó l'interès que la majoria d'estudiants van demostrar en tot moment, que anava des de la satisfació de poder relligar certes llacunes històriques fins a l'admiració que cada conferenciant o ponent va despertar. El ponents de les conferències i els participants de les taules rodones van parlar i van respondre amb el mateix entusiasme de l'ofici de mestre, explicant com va ser possible treballar per una escola de qualitat en un context advers.

\section{Àngels Ollé Romeu \\ Didàctica de la Llengua i la Literatura}

\section{Opinió d'una alumna}

Abans que tot m'agradaria expressar la meva admiració cap a totes aquestes persones que van viure en la seva pròpia experiència la necessitat $i$ les ganes de lluitar contra el model tradicional d'escola, i que apostaren per una renovació pedagògica, per una educació democràtica, catalana i de qualitat.

He de dir que, abans de participar en les jornades, tenia quatre idees sobre la història de l'educació, sobretot la referent al segle XX. Les conferències m'han servit com a vertaderes classes magistrals vivencials, ja que he après moltes coses, i sobretot una molt essencial: m'han impregnat d'entusiasme i ganes de lluitar. Gràcies a les taules rodones vaig sentir l'acostament directe del que sempre havia sentit com a teories, junt amb la realitat viscuda. En conjunt, tot ho he trobat molt interessant, ja que he fusionat com cal un pensament teòric $\mathrm{i}$ una realitat pràctica.

Sara Gené 